\title{
CRISPR/Cas9 + AAV-mediated Intra-embryonic Gene Knocking in Mice
}

Naoaki Mizuno ${ }^{1}$, Eiji Mizutani $^{1}$, Hideyuki Sato $^{1}$, Mariko Kasai $^{1}$, Hiromitsu Nakauchi $^{1,2}$ and Tomoyuki Yamaguchi1, *

\author{
${ }^{1}$ Division of Stem Cell Therapy, Institute of Medical Science, University of Tokyo, Minato-ku, Tokyo, \\ Japan; ${ }^{2}$ Institute for Stem Cell Biology and Regenerative Medicine, Department of Genetics, Stanford \\ University School of Medicine, Stanford, California, USA \\ *For correspondence: tomoyama@ims.u-tokyo.ac.jp
}

[Abstract] Intra-embryo genome editing by CRISPR/Cas9 has enabled rapid generation of gene knockout animals. However, large fragment knock-in directly into embryos' genome is still difficult, especially without microinjection of donor DNA. Viral vectors are good transporters of knock-in donor DNA for cell lines, but seemed unsuitable for pre-implantation embryos with zona pellucida, glycoprotein membrane surrounding early embryos. We found adeno-associated virus (AAV) can infect zygotes of various mammals through intact zona pellucida. AAV-mediated donor DNA delivery following Cas9 ribonucleoprotein electroporation enables large fragment knock-in without micromanipulation.

Keywords: CRISPR/Cas9, Adeno-associated viral vector, Trans-zona pellucida, Intra-embryo genome editing, Ribonucleoprotein electroporation, Large fragment knock-in

[Background] Genome editing techniques, particularly the clustered regularly interspaced short palindromic repeats (CRISPR)-associated protein 9 (CRISPR/Cas9) technology, have significantly simplified the generation of transgenic animals. Conventionally, site-directed transgenesis of mice and rats was developed by founder chimeras with genetically modified pluripotent stem cells, which potentially contribute to the germline. However, this conventional strategy is labor-intensive and does not guarantee the germline transmission. Recently, genome editing has enabled site-directed mutagenesis by allowing the direct introduction of required components into embryos at a 1-cell stage. This alternative strategy eliminates the need for any transgenic donor cells, thus resulting in the rapid generation of founder rodents. The genome editing components Cas9 and guide RNA (gRNA) in the CRISPR/Cas9 system, are introduced by microinjection into the zygote pronucleus. Although an intra-embryonic microinjection requires advanced training and expensive micromanipulation equipment, it has enabled the gene-knockout as well as knock-in of large-fragments (Yoshimi et al., 2016; Miura et al., 2018). Alternatively, CRISPR/Cas9 ribonucleoprotein-mediated editing in zygotes can be performed by electroporation; however, large fragment knock-in cannot be efficiently performed (Chen et al., 2016; Hashimoto et al., 2016). The difference between Cas9 RNP-mediated gene knock-in and knockout is the presence of knock-in donor DNA. The donor DNA must be transported inside the cell nucleus; however, this is challenging because of the requirement of a driving force for transport from the cytosol to nucleus as opposed to Cas9 RNP with a nuclear localization signal. Unlike direct microinjection into the pronucleus, electroporation may not introduce a sufficient amount of the donor 
DNA into the pronucleus. Theoretically, DNA viral vectors are efficient transporters of knock-in donor DNA because they can transfer their genomic DNA to host cells' nucleus where the in-transit nuclease-mediated degradation of DNA is prevented. However, this strategy seemed unsuitable for pre-implantation embryos possessing a zona pellucida, which inhibits viral infection. In recent studies, we and other groups found AAV can infect mice zygotes with intact zona pellucida (Mizuno et al., 2018; Yoon et al., 2018). We have successfully performed knock-in of a large fragment directly into mice embryos via CRISPR/Cas9 RNP electroporation following a trans-zona pellucida delivery of donor DNA using AAV vectors. Here, we demonstrate a detailed protocol for AAV-mediated intra-embryo knock-in in laboratory mice. This technique does not require either micromanipulation or germline competent pluripotent stem cells, which are successfully established only for rodents to date. AAV can infect various mammalian zygotes, including rats and cows. Thus, this simple genome editing method could be potentially applied to several species.

\section{Materials and Reagents}

1. $15 \mathrm{ml}$ tube (TPP, catalog number: 91015)

2. $50 \mathrm{ml}$ tube (Hitachi, catalog number: S307904A)

3. $1.5 \mathrm{ml}$ tube (Simport, catalog number: T332-5S)

4. Millex-GV Syringe Filter Unit, $0.22 \mu \mathrm{m}$, PVDF, $33 \mathrm{~mm}$ (Merck, catalog number: SLGV033RB)

5. Millex-HV Syringe Filter Unit, $0.45 \mu \mathrm{m}$, PVDF, $33 \mathrm{~mm}$ (Merck, catalog number: SLHV033RS)

6. $10 \mathrm{ml}$ syringe (Terumo, catalog number: SS-10SZ)

7. P200 Tip (QSP, catalog number: 110RL-NEW)

8. P1000 Tip (Rikaken, catalog number: RST-4810BR)

9. $5 \mathrm{ml}$ pipette (Nunc, catalog number: $170355 \mathrm{~N}$ )

10. $10 \mathrm{ml}$ pipette (Nunc, catalog number: $170356 \mathrm{~N}$ )

11. Aspirating pipette (Corning, catalog number: 357558)

12. $10 \mathrm{~cm}$ culture dish (TPP, catalog number: 93100)

13. PCR tube (FastGene, catalog number: FG-0028DC/SE)

14. $35 \mathrm{~mm}$ culture dish, non-treated (Iwaki, catalog number: 1000-035)

15. Fine glass pipette (Prepared in the laboratory, made of glass tube, ERMA, catalog number: 05-791-0)

16. Amicon Ultra-4, 100 kDa (Merck, catalog number: UFC810024)

17. C57BL/6N male mice (Japan SLC)

18. B6D2F1 female mice (Japan SLC)

19. ICR female mice (Japan SLC)

20. 293T cell (Clontech, catalog number: 632180)

21. Recombinant $A A \bigvee$ vector plasmid (for your knock-in cassette flanked by homology arms toward your gene of interest)

22. pAAM-MCS2 (recombinant AAV vector backbone, a gift from Steve Jackson, Addgene, 
Addgene plasmid number: 46954)

23. pDGM6 (a gift from David Russell, Addgene, Addgene plasmid number: 110660)

24. Cas9 protein (IDT, catalog number: 1074182)

25. crRNA (IDT, AltR grade, for your gRNA sequence)

26. tracrRNA (IDT, catalog number: 1072533)

27. DMEM (SIGMA, catalog number: D5796-500ML)

28. FBS (Gibco, catalog number: 10437-028)

29. L-Glutamine-Penicillin-Streptomycin solution (SIGMA, catalog number: G1146-100ML)

30. Trypsin-EDTA (0.05\%), phenol red (Thermo, catalog number: 25300-120)

31. Distilled water (Wako, catalog number: 043-16785)

32. BES (SIGMA, catalog number: B4554)

33. $\mathrm{NaCl}$ (SIGMA, catalog number: 28-2270-5)

34. $\mathrm{Na}_{2} \mathrm{HPO}_{4}$ (Wako, catalog number: 197-02865)

35. $\mathrm{NaOH}$ (Wako, catalog number: 198-13765)

36. $\mathrm{CaCl}_{2} \cdot 2 \mathrm{H}_{2} \mathrm{O}$ (Wako, catalog number: 031-00435)

37. AAVpro Purification Kit (All Serotypes) (Takara, catalog number: 6666) (This kit contains AAV Extraction Solution A plus, AAV Extraction Solution B, Cryonase Cold-active Nuclease, Precipitator $A$, and Precipitator $B$ )

38. EDTA-2Na.2 $\mathrm{H}_{2} \mathrm{O}$ (SIGMA, catalog number: 09-1420-5)

39. 10x D-PBS(-) (KCl $0.2 \%$ w/v, $\mathrm{KH}_{2} \mathrm{PO}_{4} 0.2 \% \mathrm{w} / \mathrm{v}, \mathrm{NaCl} 8.0 \% \mathrm{w} / \mathrm{v}, \mathrm{Na}_{2} \mathrm{HPO}_{4} 1.15 \% \mathrm{w} / \mathrm{v}, \mathrm{pH}$ 7.1-7.7) (Wako, catalog number: 048-29805)

40. M2 medium (Merck Millipore, catalog number: MR-015P-5D)

41. KSOM (Merck Millipore, catalog number: MR-020P-5D)

42. Mineral oil (SIGMA, catalog number: M8410-1L)

43. MEM-EAA (Gibco, catalog number: 11130-051)

44. MEM-NEAA (Gibco, catalog number: 11140-050)

45. Hyaluronidase (SIGMA, catalog number: H4272-30MG)

46. Opti-MEM I medium (Gibco, catalog number: 31985-062)

47. Pregnant mare serum gonadotropin (PMSG) (Aska Pharmacies)

48. Human chorionic gonadotropin (hCG) (Aska Pharmacies)

49. 1X PBS (see Recipes)

50. DMEM supplemented with 10\% FBS (see Recipes)

51. $2 \times$ BBS (see Recipes)

52. $150 \mathrm{mM} \mathrm{Na}_{2} \mathrm{HPO}_{4}$ (see Recipes)

53. $2.5 \mathrm{M} \mathrm{CaCl}_{2}$ (see Recipes)

54. 0.5 M EDTA (pH 8.0) (see Recipes)

55. KSOM-AA medium (see Recipes) 


\section{Equipment}

1. P20 pipette (GILSON, catalog number: F123600)

2. P200 pipette (GILSON, catalog number: F123601)

3. P1000 pipette (GILSON, catalog number: F123602)

4. $37.0^{\circ} \mathrm{C}$ bath (lab armor, catalog number: M714)

5. Centrifuge (TOMY, catalog number: $A X-310)$

6. Centrifuge (HITACHI, catalog number: CR21GII)

7. Thermal cycler (Takara, catalog number: TP350)

8. Electroporator (BEX, catalog number: GEB15)

9. $1 \mathrm{~mm}$ gap electrode (BEX, catalog number: LF501PT1-10)

10. Stereoscopic microscope (Nikon, model: SMZ1000)

11. Thermo plate for microscope (TOKAI HIT, model: TP-SMZSL)

12. Anaesthetic vaporizer (Muromachi Kikai, model: MK-A110)

13. $\mathrm{CO}_{2}$ incubator (Wakenyaku, model: $9300 \mathrm{E}$ )

14. $-80^{\circ} \mathrm{C}$ freezer (Panasonic, model: MDF-U700VX-PJ)

\section{Procedure}

A. AAV vector plasmid construction

1. Design your AAV vector plasmid and construct it by conventional molecular biological techniques (Green et al., 2012; Behringer et al., 2003). Empty backbone of AAV vector, pAAV-MCS2, is deposited to Addgene.

2. Insert your knock-in cassette flanked by $5^{\prime}$ and $3^{\prime}$ homology arms into your gene of interest between AAV inverted terminal repeats (ITRs). We recommend 300-1,000 bp homology arms for each side, but 100 bp homology arms are still sufficient for the knock-in.

Note: AAV genome size (sequence length between ITRs on both ends) should be smaller than $4.8 \mathrm{~kb}$.

B. AAV vector production, extraction and purification

\section{Day 0:}

1. Seed 4.0-4.5 x $10^{6} 293 \mathrm{~T}$ cells $/ 10 \mathrm{~cm}$ dish with $10 \mathrm{ml}$ DMEM supplemented with $10 \%$ FBS. Prepare 8 dishes.

2. Incubate in a $37.0^{\circ} \mathrm{C}, 10 \% \mathrm{CO}_{2}$ incubator (or $5 \%$ incubator, alternatively).

\section{Day 1:}

1. Incubate sterile distilled water, $2.5 \mathrm{M} \mathrm{CaCl}_{2}, 2 \mathrm{x}$ BBS in a $37.0{ }^{\circ} \mathrm{C}$ bath for $30-60 \mathrm{~min}$. Vortex briefly.

2. Add $80 \mu \mathrm{l}$ AAV plasmid $(1 \mathrm{mg} / \mathrm{ml})$ and $200 \mu \mathrm{l}$ pDGM6 $(1 \mathrm{mg} / \mathrm{ml})$ into $3,320 \mu \mathrm{l}$ sterile distilled 
water in a $15 \mathrm{ml}$ tube $(10 \mu \mathrm{l}$ AAV plasmid, $25 \mu \mathrm{l}$ pDGM6, $415 \mu \mathrm{l}$ sterile distilled water for one $10 \mathrm{~cm}$ dish transfection, respectively). Vortex briefly.

3. Add $400 \mu \mathrm{l} 2.5 \mathrm{M} \mathrm{CaCl}_{2}$ solution $(50 \mu \mathrm{l}$ for each $10 \mathrm{~cm}$ dish transfection) into the $15 \mathrm{ml}$ tuble containting plasmids. Immediately vortex for $10 \mathrm{~s}$.

4. After vortexing, immediately add $4 \mathrm{ml} 2 x$ BBS (500 $\mu \mathrm{l}$ for one $10 \mathrm{~cm}$ dish transfection), and then shake the $15 \mathrm{ml}$ tubes vigorously. Alternatively, add 2x BBS into the $15 \mathrm{ml}$ tube under continuous vortexing.

5. Incubate at RT for 20 min.

6. Add $1 \mathrm{ml}$ transfection solution (prepared on Procedure B Day 1: Steps 1 to 5) to each $10 \mathrm{~cm}$ dish.

7. Incubate in a $37.0{ }^{\circ} \mathrm{C}, 3 \% \mathrm{CO}_{2}$ incubator (or $5 \%$ incubator, alternatively).

\section{Day 2:}

1. Aspirate medium containing transfection solution, and add $5 \mathrm{ml} \mathrm{DMEM}$ supplemented with $10 \%$ FBS with a $5 \mathrm{ml}$ pipette.

2. Incubate in a $37.0^{\circ} \mathrm{C}, 10 \% \mathrm{CO}_{2}$ incubator (or $5 \%$ incubator, alternatively) until Day 4 .

\section{Day 4:}

1. Add $\times 1 / 80$ volume of $0.5 \mathrm{M}$ EDTA $(\mathrm{pH} 8.0)(62.5 \mu \mathrm{l}$ into $5 \mathrm{ml}$ medium per $10 \mathrm{~cm}$ dish).

2. Incubate at RT for $10 \mathrm{~min}$. The cells would be detached from the dish after incubation.

3. Collect 293T cells and culture medium into a $50 \mathrm{ml}$ tube with a $10 \mathrm{ml}$ pipette.

4. Centrifuge at $4{ }^{\circ} \mathrm{C}, 1,700-2,000 \times g, 10 \mathrm{~min}$.

5. Aspirate supernatant.

6. Centrifuge at $4{ }^{\circ} \mathrm{C}, 1,700-2,000 \times g, 1$ min to collect residual medium.

7. Aspirate supernatant completely.

8. Vortex the $50 \mathrm{ml}$ tube and dissociate cell pellet.

9. Add $4 \mathrm{ml}$ AAV Extraction Solution A plus $(0.5 \mathrm{ml}$ for each $10 \mathrm{~cm}$ dish transfection).

10. Vortex for $15 \mathrm{~s}$.

11. Incubate at RT for $5 \mathrm{~min}$.

12. Vortex again for $15 \mathrm{~s}$.

13. Incubate at RT for another 5 min.

14. Vortex again for $15 \mathrm{~s}$.

15. Centrifuge the $50 \mathrm{ml}$ tube at $4{ }^{\circ} \mathrm{C}, 9,000 \times \mathrm{g}, 10 \mathrm{~min}$.

16. Transfer the supernatant to a fresh $50 \mathrm{ml}$ tube with a P1000 tip pipette.

17. Add $400 \mu$ IAV Extraction Solution B ( $10 \%$ volume of AAV Extraction Solution A plus), and mix it gently.

18. Add $40 \mu$ l Cryonase Cold-active Nuclease (1\% volume of AAV Extraction Solution A plus), and mix it gently.

19. Incubate at $37.0^{\circ} \mathrm{C}$ for $60 \mathrm{~min}$. 
20. Add $400 \mu$ Precipitator A (10\% volume of AAV Extraction Solution A plus).

21. Vortex for $10 \mathrm{~s}$.

22. Incubate at $37.0^{\circ} \mathrm{C}$ for $30 \mathrm{~min}$.

23. Vortex for $10 \mathrm{~s}$.

24. Add $200 \mu \mathrm{l}$ Precipitator B (5\% volume of AAV Extraction Solution A plus).

25. Vortex for $10 \mathrm{~s}$.

26. Centrifuge at $4{ }^{\circ} \mathrm{C}, 9,000 \times \mathrm{g}, 20 \mathrm{~min}$.

27. Transfer the supernatant to a fresh $50 \mathrm{ml}$ tube with a $\mathrm{P} 1000$ tip pipette.

28. Centrifuge again at $4{ }^{\circ} \mathrm{C}, 9,000 \times g, 20 \mathrm{~min}$.

29. Transfer the supernatant to a 6-10 cm dish with a P1000 tip pipette (It might be difficult to aspirate the supernatant from the $50 \mathrm{ml}$ tube directly with a $10 \mathrm{ml}$ syringe).

30. Aspirate the supernatant with a $10 \mathrm{ml}$ syringe, and filtrate it with $0.45 \mu \mathrm{m}$ PVDF filter into a $15 \mathrm{ml}$ tube.

31. Transfer the filtered supernatant into Amicon Ultra-4, $100 \mathrm{kDa}$.

32. Centrifuge at $15{ }^{\circ} \mathrm{C}, 2,000 \times \mathrm{g}, 5 \mathrm{~min}$.

33. Discard flow-through, add $4 \mathrm{ml} 1 \times$ PBS onto the filter-unit, and centrifuge at $15{ }^{\circ} \mathrm{C}, 2,000 \times \mathrm{g}$, 5 min.

34. Repeat the previous ultrafiltration step, 7 times.

35. Collect AAV vector solution with a P200 pipette into a $1.5 \mathrm{ml}$ tube. Approximately $100-120 \mu \mathrm{l}$ of viral vector suspension would be recovered.

36. Dilute AAV vector solution with $1 \times$ PBS up to $200 \mu \mathrm{l}$, and dispense $20 \mu \mathrm{l}$ aliquots in $1.5 \mathrm{ml}$ tubes.

37. Store AAV vector solution at $-80^{\circ} \mathrm{C}$.

C. Estimation of $A A V$ vector titer

Estimate the AAV vector titer by qPCR (Lock et al., 2014; Werling et al., 2015).

D. Preparation of pronuclear-stage mice embryos

Prepare pronuclear-stage mice embryos as described previously (Behringer et al., 2003). Transfer embryos with a fine glass pipette.

1. Administer $5 \mathrm{IU} /$ mouse PMSG into B6D2F1 female mice by intraperitoneal injection at 15:00-18:00 PM.

2. Forty-eight hours after PMSG administration, administer $5 \mathrm{IU} / \mathrm{mouse}$ hCG into B6D2F1 female mice by intraperitoneal injection.

3. Immediately after hCG administration, mate female mice with C57BL/6N male mice.

4. 14-16 h after hCG injection, retrieve zygotes from oviduct, and remove surrounding cumulus cells by short-term culture and pipetting in $0.1 \%$ hyaluronidase-containing $\mathrm{M} 2$ media.

5. Incubate zygotes in $\mathrm{KSOM}-\mathrm{AA}$ medium at $37.0^{\circ} \mathrm{C}$ in $5 \% \mathrm{CO}_{2}$ in air atmosphere for $1-4 \mathrm{~h}$.

6. Collect two-pronuclear zygotes. 
E. Preparation of Cas9 RNP solution

1. Reconstitute lyophilized crRNA and tracerRNA with Opti-MEM I medium at $100 \mu \mathrm{M}$ each.

2. Mix $10 \mu$ of crRNA and an equal amount of tracrRNA in PCR tube.

3. Anneal crRNA with tracrRNA in a PCR thermal cycler. Heat it $95^{\circ} \mathrm{C}$ for $5 \mathrm{~min}$, and cool it down to $25^{\circ} \mathrm{C}$ by $5{ }^{\circ} \mathrm{C} / \mathrm{min}$, then keep it at $4{ }^{\circ} \mathrm{C}$.

4. Dilute $100 \mathrm{ng} / \mu \mathrm{l}(0.61 \mu \mathrm{M})$ Cas9 protein, $200 \mathrm{ng} / \mu \mathrm{l}(2.94 \mu \mathrm{M})$ annealed gRNA complex (crRNA + tracrRNA) in Opti-MEM I medium. Prepare enough amount of the Cas9 RNP solution; 20-30 $\mu \mathrm{l}$ to wash embryos before electroporation, and $5 \mu \mathrm{l} / \mathrm{run}$ on electroporation.

5. Keep Cas9 RNP solution on ice until the electroporation.

F. Preparation of embryo culture medium containing knock-in donor AAV vector

1. Dilute knock-in donor AAV with KSOM-AA medium at $1 \times 10^{7}-1 \times 10^{8} \mathrm{vg} / \mathrm{ml}$. We recommend $3 \times 10^{7} \mathrm{vg} / \mathrm{ml}$ for the initial trial, but optimal AAV dose should be determined empirically in each laboratory.

2. Prepare $100 \mu \mathrm{l}$ drop of KSOM-AA medium containing AAV vector for embryo transduction, and three $100 \mu \mathrm{l}$ drops of KSOM-AA medium without AAV for washing embryo after electroporation for every 40-60 embryos in a 35-mm non-treated culture dish. Cover it with mineral oil.

3. Incubate the dish at $37.0^{\circ} \mathrm{C}$ in $5 \% \mathrm{CO}_{2}$ air atmosphere for more than $30 \mathrm{~min}$.

G. Cas9 RNP electroporation and donor AAV transduction

1. Connect $1 \mathrm{~mm}$ gap electrode on stereoscopic microscope with the electroporator. DO NOT turn on the thermal plate of microscope during electroporation steps. Otherwise, electrode solution would evaporate immediately (Figure1A).

2. Wash $1 \mathrm{~mm}$ gap electrode with $5 \mu \mathrm{l}$ Opti-MEM I media, 3 times.

3. Prepare 20-30 $\mu \mathrm{l}$ drop of Cas9 RNP solution on 35-mm non-treated culture dish for washing embryos.

4. Wash 20-30 two-pronuclear zygotes with Cas9 RNP solution prepared on Step G3.

5. Add $5 \mu$ l Cas9 RNP solution on $1 \mathrm{~mm}$ gap electrode.

6. Immediately transfer 20-30 two-pronuclear zygotes on $1 \mathrm{~mm}$ gap electrode (Figure 1B).

7. Perform electroporation within $1 \mathrm{~min}$. Condition is as following: $25 \mathrm{~V}, 3 \mathrm{~ms} \mathrm{ON}, 97 \mathrm{~ms}$ OFF, Pd Alt 3-4 times.

8. Collect embryos on the electrode, and wash them with KSOM-AA medium three times.

9. Transfer embryos into KSOM-AA medium containing AAV vector.

10. Incubate embryos at $37.0^{\circ} \mathrm{C}$ in $5 \% \mathrm{CO}_{2}$ air atmosphere for $16-20 \mathrm{~h}$.

11. Repeat Steps G2-G10 for next run of electroporation. Cas9 RNP solution should be replaced with new $5 \mu$ l Cas9 RNP solution for the next 20-30 embryos.

12. Prepare pseudopregnant female by mating proestrus stage ICR female mice with ICR male mice received vasectomy.

13. Sixteen to twenty hours after electroporation, collect embryos at 2-cell stage. 
14. Wash embryos with M2 medium three times, and transfer to oviduct of E0.5 pseudopregnant females under anesthesia.
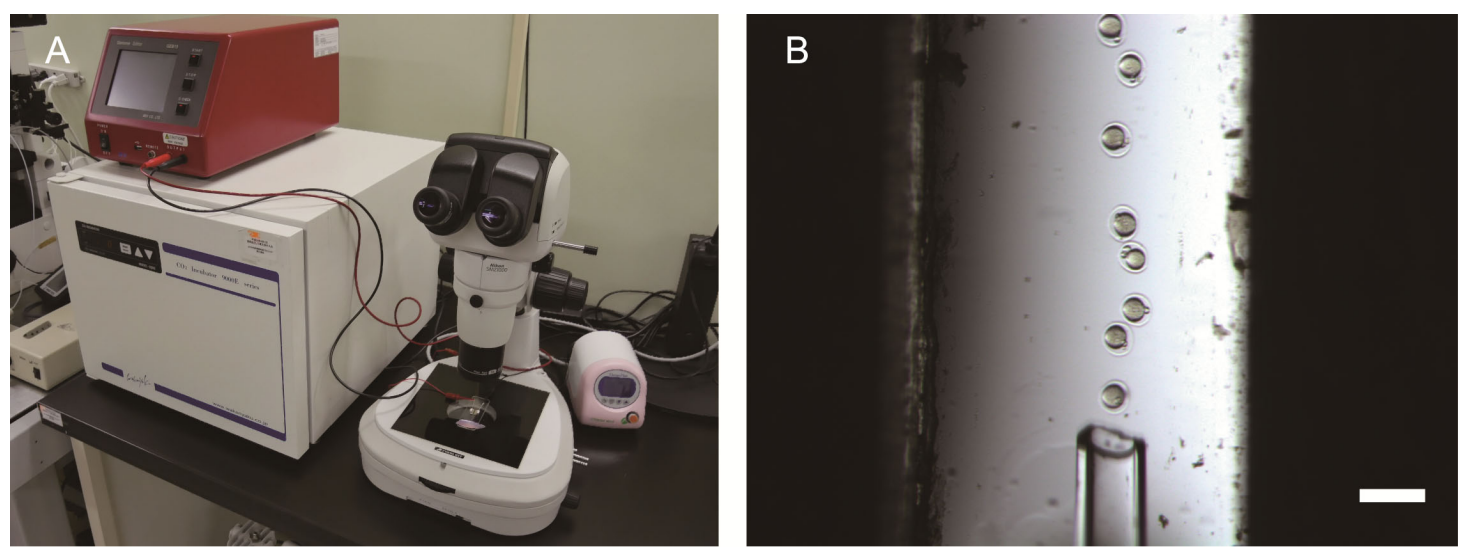

Figure 1. Cas9 RNP electroporation of mice zygotes. A. Required equipment for zygote electroporation. The $1 \mathrm{~mm}$ gap electrode on the microscope is connected to the electroporator. B. Two-pronuclear zygotes on $1 \mathrm{~mm}$ gap electrode. Scale bar, $100 \mu \mathrm{m}$.

\section{Data analysis}

The knock-in efficiency and the development rate of embryos were described in Table 2 of the original article (https://doi.org/10.1016/i.isci.2018.10.030). The knock-in efficiency blastocyst stage embryos cultured in vitro is similar to that of the offsprings. We recommend genotyping of blastocysts in preliminary experiments.

\section{$\underline{\text { Notes }}$}

1. All materials should be lot-checked for embryo culture.

2. All mice were maintained in a $12 \mathrm{~h}: 12 \mathrm{~h}$ light-dark cycle (08:00-20:00).

3. In general, we prepare 100-200 zygotes for one experiment. This is enough to obtain a founder mouse in many cases.

4. To exclude potential off-target insertion of transgenes, consider copy number estimation of the transgene on the offspring's' genome by digital PCR or conventional southern blotting.

\section{Recipes}

1. $1 \times \mathrm{PBS}$

Dilute $500 \mathrm{ml}$ 10x D-PBS(-) with $4.5 \mathrm{~L}$ distilled water

Sterilize by autoclave

2. DMEM supplemented with $10 \%$ FBS

DMEM 
10\% FBS (heat-inactivated)

1\% L-Glutamine-Penicillin-Streptomycin solution

3. $2 \times B B S$

$50 \mathrm{mM}$ BES

$280 \mathrm{mM} \mathrm{NaCl}$

$1.5 \mathrm{mM} \mathrm{Na}_{2} \mathrm{HPO}_{4}$

Adjust the $\mathrm{pH}$ to 6.95-7.2 with $\mathrm{NaOH}$

Optimal $\mathrm{pH}$ is different in each lot and laboratories

Sterilize with $0.22 \mu \mathrm{m}$ filter, and store at $-30{ }^{\circ} \mathrm{C}$

4. $150 \mathrm{mM} \mathrm{Na}_{2} \mathrm{HPO}_{4}$

Dissolve $1.065 \mathrm{~g} \mathrm{Na}_{2} \mathrm{HPO}_{4}$ in $50 \mathrm{ml}$ distilled water

5. $2.5 \mathrm{M} \mathrm{CaCl}_{2}$

Dissolve $18.38 \mathrm{~g} \mathrm{CaCl}_{2} \cdot 2 \mathrm{H}_{2} \mathrm{O}$ in $50 \mathrm{ml}$ distilled water

Sterilize with $0.22 \mu \mathrm{m}$ filter, and store at $-30{ }^{\circ} \mathrm{C}$

6. $0.5 \mathrm{M}$ EDTA (pH8.0)

a. Dissolve EDTA-2Na.2 $\mathrm{H}_{2} \mathrm{O} 93.06 \mathrm{~g}$ in $500 \mathrm{ml}$ distilled water

b. Adjust the $\mathrm{pH}$ to 8.0 with $\mathrm{NaOH}$

C. Sterilize with $0.22 \mu \mathrm{m}$ filter

7. KSOM-AA medium

1x KSOM media

1\% MEM-EAA

$0.5 \%$ MEM-NEAA

\section{Acknowledgments}

We thank F. Suchy, A. Ogawa, Dr. Toshiya Nishimura, Dr. Hideki Masaki, Dr. Sanae Hamanaka and A. Umino for helpful advice. We also thank Y. Yamamoto, J. Iwano, N. Sato, H. Tsukui for technical support, K. Okada for secretarial support, and M. Watanabe for advice in preparing the manuscript. This work was supported by grants from Leading Advanced Projects for medical innovation, Japan Agency for Medical Research and Development.

\section{Competing interests}

The authors declare no competing interests.

\section{Ethics}

All animal experiments were approved by the Institutional Animal Care and Use Committee (PA17-59, November 22th 2017 March 31th 2022), and performed in accordance with the 
Please cite this article as: Mizuno et. al., (2019). CRISPR/Cas9 + AAV-mediated Intra-embryonic Gene Knocking in Mice,Bio-protocol 9 (13): e3295. DOI:

guidelines of the University of Tokyo and the National Institute for Physiological Sciences.

\section{References}

1. Behringer, R., Gertsenstein, M., Nagy, K. V. and Nagy, A. (2003). Manipulating the mouse embryo a laboratory manual. Cold Spring Harbor Laboratory Press. New York.

2. Green, M. R. and Sambrook, J. (2012). Molecular Cloning: A Laboratory Manual. Cold Spring Harbor Laboratory Press. New York.

3. Chen, S., Lee, B., Lee, A. Y., Modzelewski, A. J. and He, L. (2016). Highly efficient mouse genome editing by CRISPR ribonucleoprotein electroporation of zygotes. J Biol Chem 291(28): 14457-14467.

4. Hashimoto, M., Yamashita, Y. and Takemoto, T. (2016). Electroporation of Cas9 protein/sgRNA into early pronuclear zygotes generates non-mosaic mutants in the mouse. Dev Biol 418(1): 1-9.

5. Lock, M., Alvira, M. R., Chen, S. J. and Wilson, J. M. (2014). Absolute determination of single-stranded and self-complementary adeno-associated viral vector genome titers by droplet digital PCR. Hum Gene Ther Methods 25(2): 115-125.

6. Miura, H., Quadros, R. M., Gurumurthy, C. B. and Ohtsuka, M. (2018). Easi-CRISPR for creating knock-in and conditional knockout mouse models using long ssDNA donors. Nat Protoc 13(1): 195-215.

7. Mizuno, N., Mizutani, E., Sato, H., Kasai, M., Ogawa, A., Suchy, F., Yamaguchi, T. and Nakauchi, H. (2018). Intra-embryo gene cassette knockin by CRISPR/Cas9-Mediated genome editing with adeno-associated viral vector. iScience 9: 286-297.

8. Werling, N. J., Satkunanathan, S., Thorpe, R. and Zhao, Y. (2015). Systematic comparison and validation of quantitative real-time PCR methods for the quantitation of adeno-associated viral products. Hum Gene Ther Methods 26(3): 82-92.

9. Yoon, Y., Wang, D., Tai, P. W. L., Riley, J., Gao, G. and Rivera-Perez, J. A. (2018). Streamlined ex vivo and in vivo genome editing in mouse embryos using recombinant adeno-associated viruses. Nat Commun 9(1): 412.

10. Yoshimi, K., Kunihiro, Y., Kaneko, T., Nagahora, H., Voigt, B. and Mashimo, T. (2016). ssODN-mediated knock-in with CRISPR-Cas for large genomic regions in zygotes. Nat Commun 7: 10431. 